\title{
Revisited: Borrelia burgdorferi sensu lato infections in hard ticks (Ixodes ricinus) in the city of Hanover (Germany)
}

Julia Tappe ${ }^{1}$, Daniela Jordan ${ }^{1}$, Elisabeth Janecek ${ }^{1}$, Volker Fingerle ${ }^{2}$ and Christina Strube ${ }^{1^{*}}$

\begin{abstract}
Background: The present study investigated the prevalence of Borrelia burgdorferi sensu lato (s.l.) genospecies in Ixodes ricinus ticks collected in Hanover, Northern Germany, in 2010. At the same time the study served as fifth-year-follow-up study for data comparison with 2005.

Methods: A total of 2100 questing ticks were collected and analysed by quantitative real-time PCR (qPCR) with subsequent species differentiation via Reverse Line Blot and Sanger sequencing. Simultaneously, results obtained in 2010 were compared to infection rates from 2005 to evaluate the development of B. burgdorferi s.l. infection rates in Hanoverian ticks.

Results: Overall, $22.7 \%(476 / 2,100)$ of collected ticks were tested positive for B. burgdorferi s.l. infections. Adult ticks showed an infection rate of $33.3 \%$ (124/372), subdivided into $29.6 \%$ (58/196) positive males and 37.5\% (66/176) positive females. Nymph and larvae infection rates were found to be $20.3 \%(344 / 1,697)$ and $25.8 \%(8 / 31)$, respectively. Species identification was successful for $59.2 \%$ (282/476) of positive ticks with B. afzelii as the most frequently detected genospecies, followed by B. garinii (including B. bavariensis) and B. spielmanii. B. burgdorferi sensu stricto (s.s.), B. bissettii, B. valaisiana and B. lusitaniae were also identified. Significant differences concerning seasonal fluctuations as well as local differences were observed. Comparing infection rates of Hanoverian ticks between years, a significant increase $(P=0.002)$ could be observed for larvae with $1.7 \%$ positives $(2 / 60)$ in 2005 and 25.8\% positives (8/31) in 2010. In the latter year, coinfections with Borrelia and Rickettsiales were detected in a total of $7.8 \%(163 / 2,100)$ of collected ticks. Of these, $7.3 \%(153 / 2,100)$ were coinfected with Rickettsia spp., $0.3 \%(7 / 2,100)$ with A. phagocytophilum and $0.1 \%(3 / 2,100)$ were coinfected with all three pathogens. Between years 2005 and 2010, no statistically significant differences in coinfection rates were found.
\end{abstract}

Conclusions: Comparing B. burgdorferi s.l. infections in Hanoverian I. ricinus ticks in 2010 with data from 2005, a statistically significant increase of infected larvae was noted, whereas the other stages revealed no statistically significant differences. Whether the increased larvae infection rate is an isolated event or results from factual circumstances, e.g. increasing effectiveness of transovarial transmission due to unknown factors, has to be evaluated in further studies.

Keywords: Borrelia burgdorferi s.I, Ixodes ricinus, Vector-borne diseases, Tick-borne diseases

\footnotetext{
* Correspondence: christina.strube@tiho-hannover.de

${ }^{1}$ Institute for Parasitology, University of Veterinary Medicine, Buenteweg 17,

30559 Hannover, Germany

Full list of author information is available at the end of the article
} 


\section{Background}

The hard tick Ixodes ricinus Linné 1758, known as vector for different pathogenic agents, serves as the main vector for spirochetes of the Borrelia burgdorferi sensu lato (s.l.) complex in Central Europe [1]. This genospecies complex includes the causative agents for Lyme borreliosis, the most frequent arthropod-borne human disease in the temperate northern hemisphere [2]. To date, 19 named spirochetes belong to the B. burgdorferi s.l. complex worldwide, however, several genospecies still remain unnamed [3-5]. In Europe, eleven genospecies of the Borrelia burgdorferi s.l. complex could be detected: B. burgdorferi sensu stricto (s.s.), B. afzelii, B. bavariensis, B. bissettii, B. garinii, B. lusitaniae, B. spielmanii, B. valaisiana, $B$. kurtenbachii (formerly included in the $B$. bissettii species), B. finlandensis and B. carolinensis [6-17]. All named species, with the exception of $B$. finlandensis and $B$. carolinensis, are implicated in different manifestations of Lyme borreliosis as, for example, erythema migrans, acrodermatitis chronica atrophicans, Lyme arthritis and neuroborreliosis $[3,5,18]$.

In Europe, several reservoir hosts for Lyme diseaseassociated Borrelia spp. are known as, for example, small rodents, hedgehogs, squirrels, lizards and various bird species [16,19-23]. Transmission of B. burgdorferi s.l. from ticks to hosts may occur through different developmental stages of $I$. ricinus, as transstadial transmission is very efficient. Even though larvae are occasionally affected, transovarial transmission in ticks seems to be inefficient [24]. Prevalence rates of B. burgdorferi s.l. in I. ricinus range from $6.1 \%$ in France to $22.5 \%$ in Western Switzerland [14,25-28]. In Germany, prevalences of Borrelia-positive questing $I$. ricinus ticks range from $3.1 \%$ in Northern Germany to $27.0 \%$ in Thuringia or locally up to $37 \%$ in Bavaria [13,29-33]. The present study was conducted to determine the Borrelia infection rate in Hanoverian ticks in 2010 and at the same time to serve as fifth-year-follow-up study to monitor changes or stagnation of tick infection rates when compared to data from 2005 [9]. For this, 2,100 ticks were collected in different recreational areas in 2010 in the northern German city of Hanover and subsequently analysed for B. burgdorferi s.l. infections.

\section{Methods}

\section{Tick material}

Questing ticks were collected each month from April to October 2010 in ten different recreation areas in the city of Hanover, the capital of the Northern German federal state Lower Saxony [34]. The city of Hanover was elected as the "German Capital of Biodiversity" in 2011 and is nicknamed "The green metropolis" as it houses numerous parks and the largest continuous urban woodland in Europe. At each sampling site, 30 ticks were collected per month resulting in 210 ticks per defined location over the sampling period and a total of 2,100 ticks overall. Tick species and developmental stages were determined microscopically based on morphological parameters [35].

\section{DNA isolation and detection of Borrelia spp.}

Genomic DNA isolation was carried out as described previously [34,36]. Genomic DNA was eluted twice with $70 \mu \mathrm{l}$ and $60 \mu \mathrm{l}$ double-distilled water, respectively, to obtain a final volume of $100 \mu \mathrm{l}$ genomic DNA. Detection of $B$. burgdorferi s.l. was achieved by minor groove binder probe-based qPCR targeting the 5S-23S intergenic spacer (IGS) region described by Strube et al. [37] with the modification that Absolute Blue QPCR low ROX mix (Thermo Fisher; containing Thermo-Start ${ }^{\mathrm{Tm}}$ DNA Polymerase) was used and tick DNA template was increased to $10 \mu \mathrm{l}$. All qPCR reactions were performed as duplicates and each run included a negative template control as well as plasmid standard positive controls containing $10^{0}-10^{6}$ copies of the Borrelia 5S-23S IGS and Ixodes ITS2 region, respectively [37]. Samples were resubjected to $\mathrm{qPCR}$ analysis, if only one well was determined positive and species identification was unsuccessful with the Reverse Line Blot (RLB). If no amplification could be detected in the second qPCR run, samples were considered as questionable positives.

\section{Identification of $B$. burgdorferi s.l. genospecies by Reverse Line Blot (RLB) and Sanger sequencing}

Species identification of Borrelia-positive tick samples was achieved by RLB. Sanger sequencing was additionally applied to samples that were determined B. garinii-positive in RLB to further differentiate between $B$. garinii and B. bavariensis.

RLB was preceded by amplification of the B. burgdorferi s.l. 5S-23S IGS region using biotin linked forward primer 5SCB and reverse primer 23SN2 (10 pmol each) as described by Rijpkema et al. [38]. For the $25 \mu \mathrm{l}$ reaction set up, $12.5 \mu \mathrm{l}$ Thermo-Start $^{\text {Ti }}$ PCR Master Mix (Thermo Scientific, Surrey, England), $1 \mu \mathrm{l}$ of each primer and $5 \mu \mathrm{l}$ tick DNA template were added to the corresponding amount of $\mathrm{H}_{2} \mathrm{O}$. Cycling conditions were based on the protocol by Burri et al. [39] with addition of a polymerase activation step $\left(15 \mathrm{~min}, 94^{\circ} \mathrm{C}\right)$. Each run included positive controls using template DNA of the following Borrelia genospecies (isolates): B. afzelii (PGau), B. bavariensis (PBi), B. bissettii (DN127), B. burgdorferi s.s. (Pka2), B. garinii (TN), B. lusitaniae (PotiB2), B. spielmanii (PHap) and $B$. valaisiana (VS116). Cross reactivity and specificity of the RLB were determined by using $B$. duttonii, $B$. recurrentis and Treponema phagedenis isolates as negative controls in addition to a non-template control. 
RLB technique was performed as described by Rijpkema et al. [38] with few modifications: PCR products were hybridized to 7 different oligonucleotide probes: $B$. afzelii (AF; $10 \mu \mathrm{M})$, B. garinii (GA; $10 \mu \mathrm{M})$, B. burgdorferi s.s. (SS; $20 \mu \mathrm{M})$ [38], B. bissettii (BISNE2; $10 \mu \mathrm{M})$, B. lusitaniae (LUSINE2; $10 \mu \mathrm{M}$ ), B. spielmanii (SpiNE3; $800 \mu \mathrm{M}$ ) [40] and B. valaisiana (VSNE; $20 \mu \mathrm{M}$ ) [41]. Moreover, a modified probe for B. burgdorferi s.l. (SL2; 5'-[AmC6T]CCATATTTTTATCTTCCATCTCTA-3'; $500 \mu \mathrm{M})$ was added as positive control for successful hybridization procedure. Furthermore, a probe for relapsing fever-like spirochetes (RFLNE; $250 \mu \mathrm{M}$ ) [40] was added to the RLB. All reactions were performed as duplicates.

Following sample hybridization as described by Rijpkema et al. [38], the membrane was washed with $2 \times$ SSPE- $0.5 \%$ SDS at $45^{\circ} \mathrm{C}$ for $15 \mathrm{~min}$, then incubated with streptavidinperoxidase for $30 \mathrm{~min}$ at $42^{\circ} \mathrm{C}$, and finally washed with $2 \times$ SSPE-0.5\% SDS for $10 \mathrm{~min}$ at $42^{\circ} \mathrm{C}$. Chemiluminescent hybridization signals were achieved by use of ECL detection reagent (GE Healthcare) and detected with Bio Imaging System MF-ChemiBIS 3.2 (Biostep, Jahnsdorf, Germany) during 2 to $10 \mathrm{~min}$ exposition (depending on signal strength). Reactions were performed as duplicates and all samples were tested at least twice.

To further differentiate between $B$. garinii and B. bavariensis, GA positive samples were reamplified and products showing visible gel bands were custom sequenced. Identification of those two species was based on four SNPs occurring in the 5S-23S IGS region of B. bavariensis and B. garinii (Figure 1).

Data was statistically analysed by application of chisquare test followed by Yates correction with SigmaStat ${ }^{\bullet}$ software (version 3.11) with subsequent Bonferroni-Holm correction. For analysis, $\alpha$ was defined with 0.05 and $\mathrm{H}_{0}$ was rejected if $\mathrm{P} \leq 0.05$. Ticks classified as questionable were included as positives in statistical analysis.

\section{Comparison of B. burgdorferi s.l. tick infection rates in 2010 vs. 2005}

To compare results concerning infection rates of different tick stages obtained in 2010 to those obtained in 2005, questionable results were added to positive tested ticks in 2005 [9]. As a result, modified 2005 data was used for analysis as follows: 153 positive adults divided into 75 male and 78 female ticks (75 positive and 3 questionable), 96 nymphs (92 positive and 4 questionable) and 2 larvae (1 positive and 1 questionable). Data of adult and nymphal stages were statistically analysed as described above. Final significances were based on corrected $\alpha$-values. To compare larval stages collected in 2005 with those collected in 2010, Fisher's exact test was used due to low sample size. Final significances were based on corrected $\alpha$-values.

\section{Coinfections of ticks with B. burgdorferi s.l. and Rickettsiales}

To analyze the tick coinfection rates with Borrelia and Rickettsiales, obtained data on B. burgdorferi s.l. infections were compared with data on infections with Rickettsiales published previously [34]. Statistical analysis of present coinfections with Rickettsia spp. or A. phagocytophilum and comparison with data from 2005 was conducted as described above. Comparison of coinfections with all three pathogens between years was carried out by using Fisher's exact Test (SigmaStat ${ }^{\oplus}$ software version 3.11).

\section{Results}

Collection of 2,100 questing ticks resulted in 372 adult ticks (196 males and 176 females), 1,697 nymphs and 31 larvae all identified as I. ricinus. A total of $22.7 \%$ (476/ $2,100)$ of collected ticks was found to be infected with B. burgdorferi s.l. Male adults showed an infection rate of $29.6 \%(58 / 196)$ whereas $37.5 \%(66 / 176)$ of female adults were determined positive resulting in an overall infection rate of $33.3 \%$ (124/372) for adult ticks. Nymphs showed an infection rate of $20.3 \%(344 / 1,697)$ and larval infection rates were determined as $25.8 \%$ (8/31). Statistically significant differences concerning developmental stages were observed between adults and nymphs $(\mathrm{P}<0.001$; $\left.\alpha_{\text {loc }}=0.017\right)$. On level below, adult males $(\mathrm{P}<0.001$; $\left.\alpha_{\text {loc }}=0.0083\right)$ as well as adult females $\left(P=0.003 ; \alpha_{\text {loc }}=0.01\right)$ were significantly more often infected than nymphs. A detailed overview of infection rates of different stages during the collection period is shown in Table 1 .

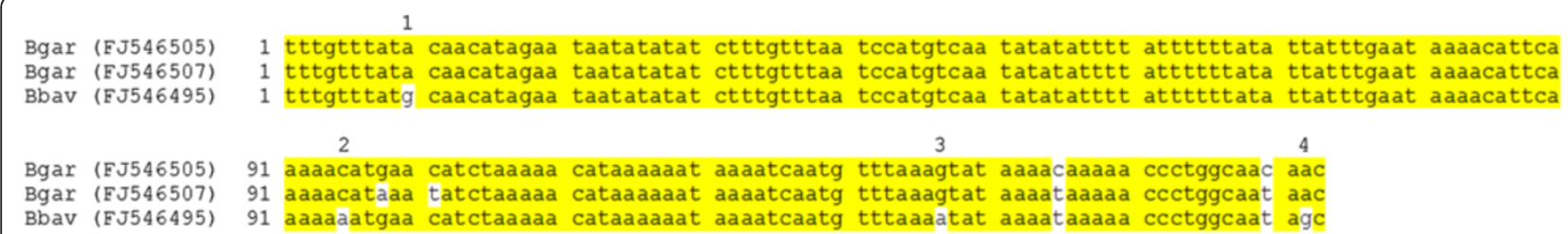

Figure 1 SNPs in the partial 5S-23S intergenic spacer region of B. garinii and B. bavariensis. SNPS used for genospecies differentiation are indicated by numbers. The displayed alignment is based on GenBank accession numbers FJ546505 (Bgar: B. garinii, strain IPT157), FJ546507 (Bgar: B. garinii, strain IPT165) and FJ546495 (Bbav: B. bavariensis, strain PBi). 
Table 1 B. burgdorferi s.l.-infected Hanoverian ticks (positive/total ticks) in 2010

\begin{tabular}{|c|c|c|c|c|c|c|c|c|}
\hline & April & May & June & July & August & September & October & Total \\
\hline Adults & $30 / 89$ & $12 / 48$ & $15 / 39$ & $12 / 41$ & $17 / 56$ & $14 / 52$ & $24 / 47$ & $124 / 372$ \\
\hline (\%) & $(33.7)$ & $(25.0)$ & $(38.5)$ & (36.6) & $(29.3)$ & $(26.9)$ & $(51.1)$ & (33.3) \\
\hline$q^{*}$ & 1 & 0 & 2 & 0 & 1 & 0 & 1 & 5 \\
\hline Thereof males & $15 / 57$ & $6 / 29$ & $8 / 19$ & $7 / 24$ & $7 / 24$ & $6 / 25$ & $9 / 18$ & $58 / 196$ \\
\hline (\%) & $(26.3)$ & $(20.7)$ & $(42.1)$ & $(37.5)$ & $(29.2)$ & $(24.0)$ & $(50.0)$ & (29.6) \\
\hline$q^{*}$ & 1 & 0 & 1 & 0 & 0 & 0 & 0 & 2 \\
\hline females & $15 / 32$ & $6 / 19$ & $7 / 20$ & $5 / 17$ & $10 / 32$ & $8 / 27$ & $15 / 29$ & $66 / 176$ \\
\hline (\%) & $(46.8)$ & (31.6) & $(35.0)$ & (35.6) & (31.3) & (29.6) & $(51.7)$ & $(37.5)$ \\
\hline$q^{*}$ & 0 & 0 & 1 & 0 & 1 & 0 & 1 & 3 \\
\hline Nymphs & $27 / 201$ & $41 / 248$ & $61 / 261$ & $47 / 259$ & $46 / 244$ & $52 / 241$ & $70 / 243$ & $344 / 1697$ \\
\hline (\%) & (13.4) & $(16.5)$ & $(23.4)$ & (26.6) & $(18.9)$ & $(21.6)$ & $(28.8)$ & $(20.3)$ \\
\hline$q^{*}$ & 4 & 5 & 4 & 2 & 2 & 4 & 4 & 25 \\
\hline Larvae & $3 / 10$ & $0 / 4$ & $0 / 0$ & $0 / 0$ & $0 / 0$ & $1 / 7$ & $4 / 10$ & $8 / 31$ \\
\hline (\%) & $(30.0)$ & $(0.0)$ & n.a. ${ }^{* *}$ & n.a. ${ }^{* *}$ & n.a. ${ }^{* *}$ & $(14.3)$ & $(40.0)$ & $(25.8)$ \\
\hline$q^{*}$ & 3 & 0 & п.а..* & n.a. ${ }^{* *}$ & n.a. ${ }^{* *}$ & 0 & 2 & 5 \\
\hline Total & $60 / 300$ & $53 / 300$ & $76 / 300$ & $59 / 300$ & $63 / 300$ & $67 / 300$ & $98 / 300$ & $476 / 2100$ \\
\hline (\%) & $(20.0)$ & $(17.7)$ & $(25.3)$ & $(28.0)$ & $(21.0)$ & $(22.3)$ & $(32.7)$ & $(22.7)$ \\
\hline$q^{*}$ & 8 & 5 & 6 & 2 & 3 & 4 & 7 & 35 \\
\hline
\end{tabular}

*q: questionable ticks. These ticks were included as positives in statistical analysis. **n.a.: not applicable.

Over the collection period, two main infection peaks of ticks could be observed with a first increase in June $(25.3 \% ; 76 / 300)$ and July $(28 \% ; 83 / 300)$ as well as a second peak in October $(32.7 \% ; 98 / 300)$, the latter is simultaneously the highest seasonal prevalence. The lowest Borrelia-prevalence was determined in May (17.7\%; 53/300). Statistically significant differences were observed between October and the months of April, May and August. P-values and adjusted $\alpha$-values are shown in Figure 2.

Concerning the distribution of infected ticks at different sampling locations, several statistical significances were observed. The highest infection rate was found at "Misburger Wald" consisting of 32.9\% $(69 / 210)$ infected ticks, followed by "Mecklenheide" $(30.0 \% ; 63 / 210)$. The locations with lowest infection rates were "Bornumer Holz" and "Maschpark" (both $16.2 \%$; 34/210) followed by "Annateiche" (16.7\%; $35 / 210)$. Statistically significant differences were determined between "Misburger Wald" vs. "Bornumer Holz", "Maschpark" and "Annateiche" as well as between "Mecklenheide" vs. "Bornumer Holz" and "Maschpark". An overview of infection rates of tick stages at all sampling locations is provided in Table 2. Adjusted $\alpha$-values and corresponding $\mathrm{P}$-values are shown in Figure 3. Borrelia spp. infection rates in ticks at the different sampling locations are visualized in Figure 4.

\section{Identification and distribution of B. burgdorferi s.l. genospecies}

In $65.5 \%(312 / 476)$ of Borrelia qPCR-positive ticks, RLB confirmed B. burgdorferi s.l. infection. Data was composed of 39 male adults, 40 female adults, 232 nymphs and 1 larva. Samples containing $\geq 10^{4} 5 \mathrm{~S}-23 \mathrm{~S}$ IGS copies showed a detection rate of $77.8 \%(7 / 9), \geq 10^{3}$ copies $95.7 \%(44 / 46), \geq 10^{2} 88.9 \%(96 / 108)$ and $\geq 10^{1}$ copies resulted in $74.2 \%(66 / 89)$ detection rate. Ticks containing $\leq 105 \mathrm{~S}-23 \mathrm{~S}$ IGS copies showed a detection rate of $44.2 \%(99 / 224)$. B. burgdorferi s.l. genospecies identification by RLB was successful in 282 of the 476 qPCR-positive ticks (59.2\%). A detailed overview of detected genospecies is given in Table 3. Overall, $B$. spielmanii, $B$. bissettii and $B$. lusitaniae were mainly associated with multiple-infections.

Out of 54 tick samples with a positive signal using the B. garinii including B. bavariensis RLB probe, 44 samples were sequenced via Sanger sequencing and revealed $18.2 \%$ (8/44) B. bavariensis, $45.5 \%$ (20/44) B. garinii and $15.9 \%(7 / 44)$ non-identifiable samples. The remaining $20.5 \%$ (9/44) samples were assigned to other genospecies (B. afzelii, B. burgdorferi s.s., B. spielmanii and 


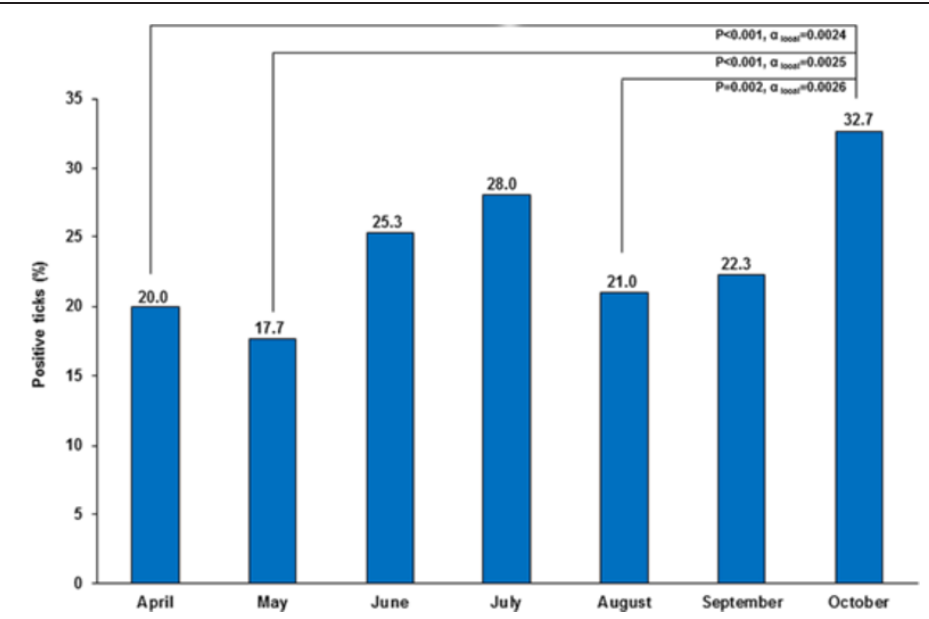

Figure 2 Seasonal variations of B. burgdorferi s.l.-infected Hanoverian ticks in 2010. Connection lines indicate significant differences between prevalence rates.

B. valaisiana) corresponding to the genospecies coinfections identified by RLB.

\section{Coinfections of ticks with B. burgdorferi s.l. and}

\section{Rickettsiales}

The total coinfection rate of the 2100 analysed samples with Rickettsiales was $7.8 \%(153 / 2,100)$. Coinfections with Rickettsia spp. [R. helvetica in all typable samples (34)] were found in $7.3 \%(153 / 2,100)$ of the examined ticks and coinfections with $A$. phagocytophilum were detected in $0.3 \%(7 / 2,100)$ of ticks. Infection with all three pathogens was found in $0.1 \%(3 / 2100)$ of samples. Adult stages $(43 / 372 ; 11.6 \%)$ were statistically significant $(\mathrm{P}=0.005$; $\left.\alpha_{\text {loc }}=0.01\right)$ more often infected with Rickettsiales than

Table 2 Distribution of B. burgdorferi s.l.-infected ticks (positives/total ticks) at different collection sites in the city of Hanover in 2010

\begin{tabular}{|c|c|c|c|c|c|c|c|c|c|c|}
\hline & Mecklenheide & $\begin{array}{l}\text { Große } \\
\text { Heide }\end{array}$ & $\begin{array}{l}\text { Misburger } \\
\text { Wald }\end{array}$ & Annateiche & $\begin{array}{c}\text { Seelhorster } \\
\text { Wald }\end{array}$ & $\begin{array}{l}\text { Ricklinger } \\
\text { Teiche }\end{array}$ & $\begin{array}{c}\text { Bornumer } \\
\text { Holz }\end{array}$ & $\begin{array}{c}\text { Georgen- } \\
\text { garten }\end{array}$ & Eilenriede & Maschpark \\
\hline Adults & $6 / 21$ & $9 / 22$ & $12 / 35$ & $10 / 27$ & $20 / 42$ & $18 / 46$ & $14 / 44$ & $19 / 53$ & $8 / 36$ & $8 / 46$ \\
\hline (\%) & (28.6) & $(40.9)$ & (34.3) & $(37.0)$ & $(47.6)$ & (39.1) & (31.8) & (35.8) & $(22.2)$ & $(17.4)$ \\
\hline$q^{*}$ & 0 & 1 & 2 & 0 & 0 & 1 & 1 & 0 & 0 & 0 \\
\hline Adult males & $2 / 12$ & $2 / 6$ & $7 / 17$ & $4 / 16$ & $7 / 19$ & $11 / 28$ & $5 / 21$ & $10 / 27$ & $6 / 26$ & $4 / 24$ \\
\hline (\%) & (16.7) & (33.3) & $(41.2)$ & $(25.0)$ & $(36.8)$ & (39.3) & $(23.8)$ & $(37.0)$ & $(23.1)$ & (16.7) \\
\hline$q^{*}$ & 0 & 0 & 1 & 0 & 0 & 1 & 0 & 0 & 0 & 0 \\
\hline Adult females & $4 / 9$ & $7 / 16$ & $5 / 18$ & $6 / 11$ & $13 / 23$ & $7 / 18$ & $9 / 23$ & $9 / 26$ & $2 / 10$ & $4 / 22$ \\
\hline (\%) & $(44.4)$ & $(43.8)$ & $(27.8)$ & $(54.5)$ & $(56.5)$ & (38.9) & (39.1) & (34.6) & $(20.0)$ & $(18.2)$ \\
\hline$q^{*}$ & 0 & 1 & 1 & 0 & 0 & 0 & 1 & 0 & 0 & 0 \\
\hline Nymphs & $57 / 186$ & $36 / 182$ & $56 / 170$ & $25 / 182$ & $32 / 168$ & $26 / 161$ & $20 / 148$ & $30 / 148$ & $36 / 171$ & $26 / 164$ \\
\hline (\%) & (30.6) & (19.8) & (32.9) & (13.7) & (19.0) & $(16.1)$ & (13.5) & $(20.3)$ & (21.1) & (15.9) \\
\hline$q^{*}$ & 4 & 2 & 3 & 2 & 3 & 3 & 3 & 2 & 1 & 2 \\
\hline Larvae & $0 / 3$ & $3 / 6$ & $1 / 5$ & $0 / 1$ & $0 / 0$ & $1 / 1$ & $0 / 1$ & $1 / 9$ & $2 / 3$ & $0 / 0$ \\
\hline (\%) & $(0.0)$ & $(50.0)$ & (20.0) & $(0.0)$ & n.a..* & $(100.0)$ & $(0.0)$ & $(11.1)$ & $(66.7)$ & п.а. ${ }^{* *}$ \\
\hline$q^{*}$ & 0 & 1 & 1 & 0 & 0 & 1 & 0 & 0 & 2 & 0 \\
\hline Total & $63 / 210$ & $48 / 210$ & $69 / 210$ & $35 / 210$ & $52 / 210$ & $45 / 210$ & $34 / 210$ & $50 / 210$ & $46 / 210$ & $34 / 210$ \\
\hline (\%) & $(30.0)$ & $(22.9)$ & (32.9) & $(16.7)$ & $(24.8)$ & $(21.4)$ & $(16.2)$ & (23.8) & (21.9) & $(16.2)$ \\
\hline$q^{*}$ & 4 & 4 & 6 & 2 & 3 & 5 & 4 & 2 & 3 & 2 \\
\hline
\end{tabular}

*q: questionable ticks. These ticks were included as positives in statistical analysis.

${ }^{* *}$ n.a.: not applicable. 


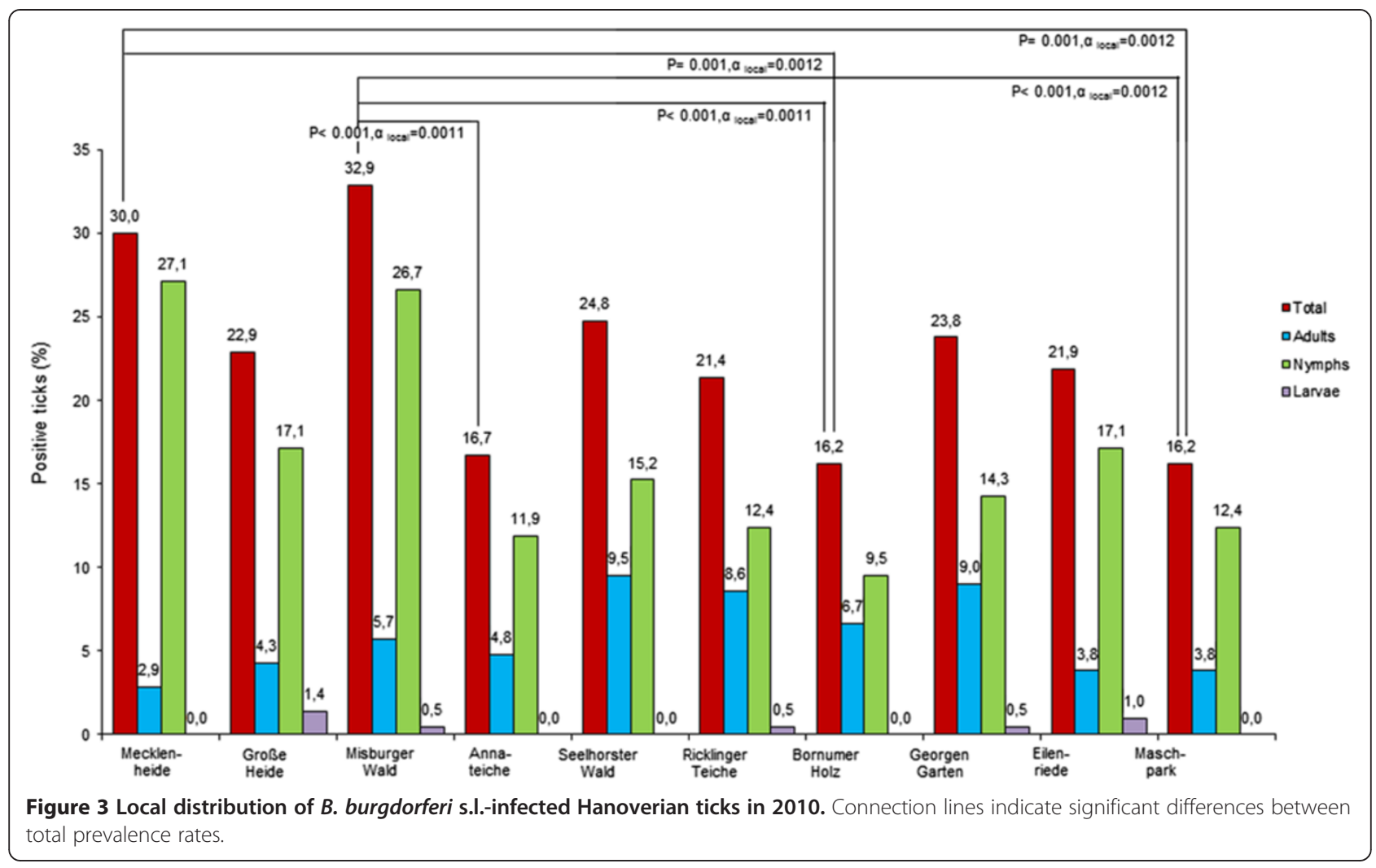

nymphs (120/1697; 7.1\%). Concerning Rickettsia spp. coinfections, statistically significant differences $(\mathrm{P}=0.002$; $\left.\alpha_{\text {loc }}=0.01\right)$ were observed between adults $(42 / 372 ; 11.3 \%)$ and nymphs $(111 / 1,697 ; 6.5 \%)$. No coinfections were found in examined larvae. A detailed overview about infection rates and tick stages is provided in Table 4.

\section{Comparison of tick infections with B. burgdorferi s.l. and} coinfections with Rickettsiales between 2010 and 2005

Comparing infection rates of Hanoverian I. ricinus ticks with Borrelia spp. 5 years apart, the infection rate of adult stages and nymphs remained mainly unchanged with $35.5 \%(153 / 433)$ and $18.9 \%(96 / 507)$ infected individuals in 2005 [9] compared to 33.3\% (124/372) and 20.3\% (344/ $1,976)$ infected individuals in 2010 . However, a statistically significant increase $(\mathrm{P}=0.002)$ was observed for larval stages with $3.3 \%(2 / 60)$ infected larvae in 2005 whereas 25.8\% (8/31) Borrelia-positive larvae were found in 2010. Concerning detection of different $B$. burgdorferi s.l. genospecies, it should be noted that in 2005, B. garinii, including $B$. bavariensis, was the most frequently detected genospecies, followed by $B$. afzelii and B. spielmanii. In 2010, B. afzelii was the most frequent detected species followed by $B$. garinii including $B$. bavariensis and $B$. spielmanii. Comparison of Borrelia spp. and Rickettsiales coinfection rates revealed no statistically significant difference between both years: Collected ticks were infected with B. burgdorferi s.l. and Rickettsia spp. at a rate of $9.1 \%$ $(99 / 1,098)$ in 2005 [42] and 7.3\% (153/2,100) in 2010. Coinfection rates with $B$. burgdorferi s.l. and $A$. phagocytophilum were $0.9 \%(15 / 1,646)$ in 2005 [43] and $0.3 \%$ $(7 / 2,100)$ in 2010 . Coinfections with all three pathogens were detected in $1.3 \%(5 / 391)$ of ticks in 2005 [42] and $0.1 \%(3 / 2,100)$ in 2010 .

\section{Discussion}

The hard tick I. ricinus serves as main vector for spirochetes of the B. burgdorferi s.l. complex in Central Europe. Parts of this complex are responsible for Lyme disease, a sickness that has increased rapidly during the past 20 years in the northern hemisphere [5,44]. In several studies, infection rates of ticks with B. burgdorferi s.l. in Germany were investigated to assess the potential infection risk for humans resulting in a broad range of infection rates ranging from $3.1 \%$ in Northern Germany to $27.0 \%$ in Thuringia and $36.2 \%$ in Bavaria [29-33]. Besides data collection in different geographical regions, it is of importance to monitor tick infection rates over time to assess whether human infection risk increases or decreases. Thus, the present study served not only as a status survey for the Northern German state capital Hanover but also as fifth-year-follow-up survey of Borrelia infections in I. ricinus ticks. 


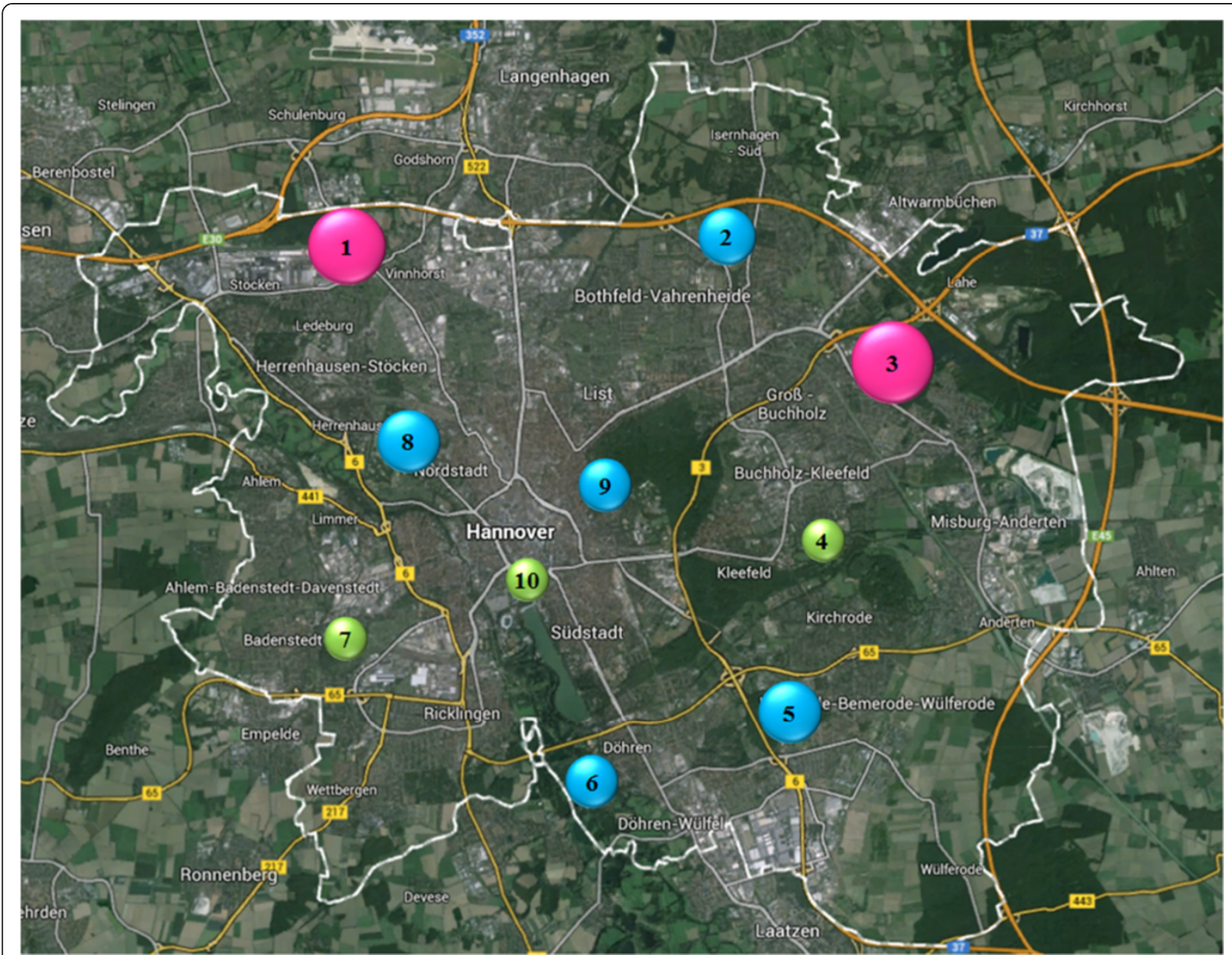

Figure 4 B. burgdorferi s.l.-infected Hanoverian ticks in 2010 at the different sampling locations. Green dots: $<20 \%$ infected ticks; blue dots: $\geq 20<30 \%$ infected ticks; pink dots: $\geq 30 \%$ infected ticks. 1: Mecklenheide; 2: Große Heide; 3: Misburger Wald; 4: Annateiche; 5: Seelhorster Wald; 6: Ricklinger Teiche; 7: Bornumer Holz; 8: Georgen Garten; 9: Eilenriede; 10: Maschpark. The white dashed line represents the city border (Map source: Google Earth).

The total infection rate of $B$. burgdorferi s.l.-infected ticks in 2010 was $22.7 \%$ with a significant difference between adults and nymphs (33.3\% and $20.3 \%$ infected individuals, respectively), but not between adults and larvae (25.8\% infected individuals). The expected highest burden in adult ticks is in accordance with different previous studies $[6,9,31]$ and is most likely related to the combination of transstadial Borrelia transmission and the number of blood meals for development, which is connected to a higher probability to acquire bacteria from infected hosts. Comparison of B. burgdorferi s.l. infection rates in I. ricinus ticks of 2010 and 2005 resulted in approximately the same percentage of infected adults (33.3\% in 2010 and $35.5 \%$ in 2005) and nymphs (20.3\% in 2010 and $18.9 \%$ in 2005) whereas tick larvae showed a significantly different $B$. burgdorferi s.l. infection rate $(\mathrm{P}=0.002)$ between 2005 (3.3\%) and 2010 (25.8\%). Due to low numbers of collected larvae (60 in 2005; 31 in
2010), the significant increase has to be verified in further studies and should be interpreted with caution. The rather high prevalence of Borrelia-infected larvae in 2010 might be explained by an interrupted blood meal with failed further development as well as by transovarial transmission. Even though transovarial transmission of $B$. burgdorferi s.l. was found to be rather inefficient $[24,45]$, it is the most plausible explanation as it seems unlikely that a quarter of collected larvae were removed during feeding from a Borrelia-infected host. However, solely in one of eight Borrelia-positive tested larvae, $B$. burgdorferi s.l. was confirmed by RLB. Overall, RLB confirmed 312 (65.5\%) out of 476 Borrelia qPCR-positive ticks and identified 282 (59.2\%) successfully concerning their genospecies. Reason for the generally lower RLBpositive rate is most likely a higher sensitivity of qPCR. The 30 tick samples in which RLB resulted in detection of B. burgdorferi s.l., but genospecies identification failed, 
Table 3 Distribution of different B. burgdorferi s.l. genospecies in positive Hanoverian ticks in 2010

\begin{tabular}{|c|c|c|c|c|c|c|c|}
\hline $\begin{array}{l}\text { Total } \\
\text { infections }\end{array}$ & $\begin{array}{l}\text { No. (\% of } \\
\text { infected ticks) }\end{array}$ & Mono-infections & $\begin{array}{l}\text { No. (\% of } \\
\text { infected ticks) }\end{array}$ & $\begin{array}{l}\text { Double- } \\
\text { infection }\end{array}$ & $\begin{array}{l}\text { No. (\% of } \\
\text { infected ticks) }\end{array}$ & $\begin{array}{l}\text { Triple-/Quadruple- } \\
\text { infection }\end{array}$ & $\begin{array}{l}\text { No. (\% of } \\
\text { infected ticks) }\end{array}$ \\
\hline Baf & $147(30.9 \%)$ & Baf & $101(21.2 \%)$ & $\mathrm{Baf}+\mathrm{Bbi}$ & $2(0.4 \%)$ & $\mathrm{Baf}+\mathrm{Bga} / \mathrm{Bba}+\mathrm{Bsp}$ & $2(0.4 \%)$ \\
\hline Bva & $46(9.7 \%)$ & Bva & $30(6.3 \%)$ & $\mathrm{Baf}+\mathrm{Bga} / \mathrm{Bba}$ & $11(2.3 \%)$ & $B a f+B s p+B s s$ & $1(0.2 \%)$ \\
\hline Bss & 47 (9.9\%) & Bss & $25(5.3 \%)$ & Baf + Blu & $2(0.4 \%)$ & Baf + Bss + Bva & $1(0.2 \%)$ \\
\hline Bga/Bba & $54(11.3 \%)$ & $\mathrm{Bga} / \mathrm{Bba}$ & $29(6.1 \%)$ & Baf + Bsp & $12(2.5 \%)$ & $\mathrm{Bbi}+\mathrm{Bga} / \mathrm{Bba}+\mathrm{Bsp}$ & $1(0.2 \%)$ \\
\hline Bsp & $52(10.9 \%)$ & Bsp & $22(4.6 \%)$ & Baf + Bss & $10(2.1 \%)$ & $\mathrm{Bga} / \mathrm{Bba}+\mathrm{Bsp}+\mathrm{Bss}$ & $1(0.2 \%)$ \\
\hline Blu & $5(1.1 \%)$ & Blu & $2(0.4 \%)$ & Baf + Bva & $4(0.8 \%)$ & $\mathrm{Baf}+\mathrm{Bga} / \mathrm{Bba}+\mathrm{Bsp}+\mathrm{Bss}$ & $1(0.2 \%)$ \\
\hline \multirow[t]{11}{*}{ Bbi } & $10(2.1 \%)$ & $\mathrm{Bbi}$ & $2(0.4 \%)$ & $\mathrm{Bga} / \mathrm{Bba}+\mathrm{Bbi}$ & $1(0.2 \%)$ & & \\
\hline & & $\begin{array}{l}\text { No genospecies } \\
\text { determined }\end{array}$ & $194(40.8 \%)$ & $\mathrm{Bga} / \mathrm{Bba}+\mathrm{Bsp}$ & $3(0.6 \%)$ & & \\
\hline & & & & $\mathrm{Bga} / \mathrm{Bba}+\mathrm{Bss}$ & $1(0.2 \%)$ & & \\
\hline & & & & $\mathrm{Bga} / \mathrm{Bba}+\mathrm{Bva}$ & $4(0.8 \%)$ & & \\
\hline & & & & $\mathrm{Bsp}+\mathrm{Bbi}$ & $2(0.4 \%)$ & & \\
\hline & & & & Bsp + Blu & $1(0.2 \%)$ & & \\
\hline & & & & Bsp + Bss & $3(0.6 \%)$ & & \\
\hline & & & & Bsp + Bva & $3(0.6 \%)$ & & \\
\hline & & & & Bss + Bbi & $1(0.2 \%)$ & & \\
\hline & & & & Bss + Bva & $3(0.6 \%)$ & & \\
\hline & & & & Bva + Bbi & $1(0.2 \%)$ & & \\
\hline
\end{tabular}

Baf: B. afzelii, Bva: B. valaisiana, Bss: B. burgdorferi s.s., Bga/Bba: B. garinii / bavariensis, Bsp: B. spielmanii, Blu: B. lusitaniae; Bbi: B. bissettii.

might be explained by the higher sensitivity of the SL2 probe compared to genospecies-specific probes. Furthermore, not all in Europe occurring B. burgdorferi s.l. genospecies were detected by RLB - probes are not available for $B$. kurtenbachii, B. carolinensis and $B$. finlandensis. Moreover, ticks might have been infected with Borrelia miyamotoi, a Borrelia species associated with the relapsing fever group. B. miyamotoi, originally detected in Japan in I. persulcatus [46], was also previously found in $I$. ricinus ticks in Europe $[47,48]$. In contrast to B. burgdorferi s.l., transovarial transmission could be demonstrated $[49,50]$. However, the primerprobe-combination [9] used in the present study does not detect B. miyamotoi, but it is specific for the B. burgdorferi s.l. complex.
Regarding seasonal distribution of B. burgdorferi s.l. infection in Hanoverian $I$. ricinus ticks, the two peak course of infected ticks in June/July and October may depend on biological and climatic conditions like host disposability, temperature and humidity as these factors can affect pathogen transmission from hosts to ticks [51-54]. Concerning different sampling sites in the city of Hanover, tick infection rates range from $16.2 \%$ at the location "Maschpark" up to $32.9 \%$ at "Misburger Wald". These differences in numbers of Borrelia-infected ticks might be explained by different incidences of Borreliainfected hosts like small rodents or birds at single sampling locations.

B. burgdorferi s.l. genospecies identification resulted in findings comparable to results from previous studies,

Table 4 Coinfections with B. burgdorferi s.l. and Rickettsiales in Hanoverian ticks in 2010

\begin{tabular}{|c|c|c|c|c|c|c|}
\hline & $\begin{array}{l}\text { No. of } \\
\text { collected ticks }\end{array}$ & $\begin{array}{l}\text { No. of } B \text {. burgdorferi } \\
\text { s.l. positive ticks }\end{array}$ & $\begin{array}{l}\text { Total } \\
\text { coinfections }\end{array}$ & $\begin{array}{l}\text { Rickettsia spp. } \\
\text { coinfections }\end{array}$ & $\begin{array}{l}\text { A. phagocytophilum } \\
\text { coinfections }\end{array}$ & $\begin{array}{l}\text { Coinfections with Rickettsia } \\
\text { spp. and } A \text {. phagocytophilum }\end{array}$ \\
\hline & & No. (\%) & No. (\%) & No. (\%) & No. (\%) & No. (\%) \\
\hline Adults & 372 & $124(33.3)$ & 43 (11.6) & $42(11.3)$ & $1(0.3)$ & $0\left(n \cdot a^{*}.\right)$ \\
\hline Males & 196 & $58(29.6)$ & $22(11.2)$ & $22(11.2)$ & $0\left(n \cdot a^{*}.\right)$ & $0\left(n . a^{*}.\right)$ \\
\hline Females & 176 & 66 (37.5) & $21(11.9)$ & $20(11.4)$ & $1(0.6)$ & $0\left(n \cdot a^{*}.\right)$ \\
\hline Nymphs & 1697 & $344(20.3)$ & $120(7.1)$ & $111(6.5)$ & $6(0.4)$ & $3(0.2)$ \\
\hline Larvae & 31 & $8(25.8)$ & 0 (n.a20F0.) & $0\left(\right.$ n. $\left.a^{*}.\right)$ & $0\left(n \cdot a^{*}.\right)$ & $0\left(\right.$ n. $\left.a^{*}.\right)$ \\
\hline All stages & 2100 & $476(22.7)$ & $163(7.8)$ & $153(7.3)$ & $7(0.3)$ & $3(0.1)$ \\
\hline
\end{tabular}

*n.a.: not applicable. 
where $B$. afzelii was the predominant detected species in ticks $[33,55,56]$, but also B. garinii including B. bavariensis and $B$. spielmanii were frequent findings in Borreliainfected $I$. ricinus ticks $[6,12,55]$. Comparing mentioned genospecies distribution in 2010 with data from Hanoverian ticks collected in 2005, B. afzelii, B. garinii including $B$. bavariensis and $B$. spielmanii were the most frequently detected species in both studies. B. afzelii was the most mono-infecting species, B. spielmanii was found more often in multiple-infections than as mono-infecting species and frequent findings of double-infections contained a combination of B. afzelii and B. spielmanii [9]. Doubleor multiple-infections (cf. Table 3) may result from blood meals on different hosts each infected with one genospecies, from one host having a multiple infection causing ticks to take up a number of genospecies, or from cofeeding of infected ticks. Several combinations including B. afzelii or B. garinii as detected in the present study were also observed by Pichon et al. [57]. The detected combination of B. afzelii and B. burgdorferi s.s. was also described amongst others in red squirrels [23].

Concerning coinfections of Borrelia-positive ticks with Rickettsiales in 2010, statistically significant differences were observed between different tick stages. This is in accordance with data from 2005, where adult ticks also showed higher infection rates than nymphs $[42,43]$. No statistically significant differences in coinfection rates were found between years.

\section{Conclusion}

In summary, comparing B. burgdorferi s.l. infections in Hanoverian I. ricinus ticks in 2010 with data from 2005, a significant increase of infected larvae was determined whereas nymphs and adult ticks did not show significantly changed infection rates. Whether this development of infected larvae is an actual fact through rather effective transovarial transmission under field conditions due to unknown factors, or an isolated event should be evaluated by further studies. The Hanoverian tick infection rate and distribution of B. afzelii, B. garinii and B. spielmanii as most abundant genospecies will be further monitored in the next fifth-year-follow-up study starting in April 2015.

\section{Competing interests}

The authors declare that they have no competing interests.

\section{Authors' contributions}

JT collected the biological material and carried out DNA isolation, GPCR and bioinformatic analyses. EJ participated in DNA isolation and DJ carried out RLB. JT and EJ drafted the manuscript. CS designed and coordinated the study. VF provided isolates of $B$. burgdorferi s.l. genospecies, $B$. duttonii, $B$. recurrentis and $T$. phagedenis for RLB. All authors participated in data analysis and interpretation and read and approved the final manuscript.

\section{Author details}

${ }^{1}$ Institute for Parasitology, University of Veterinary Medicine, Buenteweg 17, 30559 Hannover, Germany. 'erman National Reference Centre for Borrelia, Veterinärstraße 2, 85764 Oberschleißheim, Germany.
Received: 28 April 2014 Accepted: 25 August 2014

Published: 18 September 2014

\section{References}

1. Gern L, Humair PF: Ecology of Borrelia burgdorferi sensu lato in Europe In Lyme Borreliosis: Biology, Epidemiology and Control. Edited by Gray J, Kahl O, Lane RS, Stanek G. UK: CAB International Verlag; 2002:149-174.

2. Stanek G, Wormser GP, Gray J, Strle F: Lyme borreliosis. Lancet 2012, 379:461-473.

3. Rudenko N, Golovchenko M, Grubhoffer L, Oliver JH Jr: Updates on Borrelia burgdorferi sensu lato complex with respect to public health. Ticks Tick Borne Dis 2011, 2:123-128.

4. Postic D, Garnier M, Baranton G: Multilocus sequence analysis of atypical Borrelia burgdorferi sensu lato isolates-description of Borrelia californiensis sp. nov., and genomospecies 1 and 2. Int J Med Microbiol 2007, 297:263-271.

5. Franke J, Hildebrandt A, Dorn W: Exploring gaps in our knowledge on Lyme borreliosis spirochaetes-updates on complex heterogeneity, ecology, and pathogenicity. Ticks Tick Borne Dis 2013, 4:11-25.

6. Hildebrandt A, Schmidt KH, Wilske B, Dorn W, Straube E, Fingerle V: Prevalence of four species of Borrelia burgdorferi sensu lato and coinfection with Anaplasma phagocytophila in Ixodes ricinus ticks in central Germany. Eur J Clin Microbiol Infect Dis 2003, 22:364-367.

7. Rudenko N, Golovchenko M, Mokracek A, Piskunova N, Ruzek D, Mallatova N, Grubhoffer L: Detection of Borrelia bissettii in cardiac valve tissue of a patient with endocarditis and aortic valve stenosis in the Czech Republic. J Clin Microbiol 2008, 46:3540-3543.

8. Rudenko N, Golovchenko M, Ruzek D, Piskunova N, Mallatova N, Grubhoffer $\mathrm{L}$ : Molecular detection of Borrelia bissettii DNA in serum samples from patients in the Czech Republic with suspected borreliosis. FEMS Microbiol Lett 2009, 292:274-281

9. Strube C, Montenegro VM, Epe C, Eckelt E, Schnieder T: Establishment of a minor groove binder-probe based quantitative real time PCR to detect Borrelia burgdorferi sensu lato and differentiation of Borrelia spielmanii by ospA-specific conventional PCR. Parasit Vectors 2010, 3:69.

10. Collares-Pereira M, Couceiro S, Franca I, Kurtenbach K, Schafer SM, Vitorino L, Goncalves L, Baptista S, Vieira ML, Cunha C: First isolation of Borrelia lusitaniae from a human patient. J Clin Microbiol 2004, 42:1316-1318.

11. Richter D, Schroder B, Hartmann NK, Matuschka FR: Spatial stratification of various Lyme disease spirochetes in a Central European site. FEMS Microbiol Ecol 2012, 83:738-744

12. Fingerle V, Schulte-Spechtel UC, Ruzic-Sabljic E, Leonhard S, Hofmann H, Weber K, Pfister K, Strle F, Wilske B: Epidemiological aspects and molecular characterization of Borrelia burgdorferi s.l. from southern Germany with special respect to the new species Borrelia spielmanii sp. nov. Int J Med Microbiol 2008, 298:279-290.

13. Margos G, Vollmer SA, Cornet M, Garnier M, Fingerle V, Wilske B, Bormane A, Vitorino L, Collares-Pereira M, Drancourt M, Kurtenbach K: A new Borrelia species defined by multilocus sequence analysis of housekeeping genes. Appl Environ Microbiol 2009, 75:5410-5416.

14. Cotte V, Bonnet S, Cote M, Vayssier-Taussat M: Prevalence of five pathogenic agents in questing Ixodes ricinus ticks from western France. Vector Borne Zoonotic Dis 2010, 10:723-730.

15. Casjens SR, Fraser-Liggett CM, Mongodin EF, Qiu WG, Dunn JJ, Luft BJ, Schutzer SE: Whole genome sequence of an unusual Borrelia burgdorferi sensu lato isolate. J Bacterio/ 2011, 193:1489-1490.

16. Skuballa J, Petney T, Pfaffle M, Oehme R, Hartelt K, Fingerle V, Kimmig P, Taraschewski H: Occurrence of different Borrelia burgdorferi sensu lato genospecies including B. afzelii, B. bavariensis, and B. spielmanii in hedgehogs (Erinaceus spp.) in Europe. Ticks Tick Borne Dis 2012, 3:8-13.

17. Margos G, Piesman J, Lane RS, Ogden NH, Sing A, Straubinger RK, Fingerle $\mathrm{V}$ : Borrelia kurtenbachii sp. nov., a widely distributed member of the Borrelia burgdorferi sensu lato species complex in North America. Int J Syst Evol Microbiol 2014, 64:128-130.

18. Stanek G, Reiter M: The expanding Lyme Borrelia complex-clinical significance of genomic species? Clin Microbiol Infect 2011, 17:487-493.

19. Parola $P$, Raoult D: Tick-borne bacterial diseases emerging in Europe. Clin Microbiol Infect 2001, 7:80-83.

20. Franke J, Fritzsch J, Tomaso H, Straube E, Dorn W, Hildebrandt A: Coexistence of pathogens in host-seeking and feeding ticks within a 
single natural habitat in Central Germany. Appl Environ Microbiol 2010, 76:6829-6836.

21. Gern L, Estrada-Pena A, Frandsen F, Gray JS, Jaenson TG, Jongejan F, Kahl O, Korenberg E, Mehl R, Nuttall PA: European reservoir hosts of Borrelia burgdorferi sensu lato. Zentralbl Bakteriol 1998, 287:196-204.

22. Foldvari G, Rigo K, Majlathova V, Majlath I, Farkas R, Pet'ko B: Detection of Borrelia burgdorferi sensu lato in lizards and their ticks from Hungary. Vector Borne Zoonotic Dis 2009, 9:331-336.

23. Humair PF, Gern L: Relationship between Borrelia burgdorferi sensu lato species, red squirrels (Sciurus vulgaris) and Ixodes ricinus in enzootic areas in Switzerland. Acta Trop 1998, 69:213-227.

24. Nefedova W, Korenberg El, Gorelova NB, Kovalevskii YV: Studies on the transovarial transmission of Borrelia burgdorferi sensu lato in the taiga tick Ixodes persulcatus. Folia Parasitol (Praha) 2004, 51:67-71.

25. Soleng A, Kjelland V: Borrelia burgdorferi sensu lato and Anaplasma phagocytophilum in Ixodes ricinus ticks in Bronnoysund in northern Norway. Ticks Tick Borne Dis 2013, 4:218-221.

26. Lommano E, Bertaiola L, Dupasquier C, Gern L: Infections and coinfections of questing Ixodes ricinus ticks by emerging zoonotic pathogens in Western Switzerland. Appl Environ Microbiol 2012, 78:4606-4612.

27. Bettridge J, Renard M, Zhao F, Bown KJ, Birtles RJ: Distribution of Borrelia burgdorferi sensu lato in Ixodes ricinus populations across central Britain Vector Borne Zoonotic Dis 2013, 13:139-146.

28. Corrain R, Drigo M, Fenati M, Menandro ML, Mondin A, Pasotto D, Martini M: Study on ticks and tick-borne zoonoses in public parks in Italy. Zoonoses Public Health 2012, 59:468-476.

29. Franke J, Hildebrandt A, Meier F, Straube E, Dorn W: Prevalence of Lyme disease agents and several emerging pathogens in questing ticks from the German Baltic coast. J Med Entomol 2011, 48:441-444

30. Schwarz A, Honig V, Vavruskova Z, Grubhoffer L, Balczun C, Albring A, Schaub GA: Abundance of Ixodes ricinus and prevalence of Borrelia burgdorferi s.l. in the nature reserve Siebengebirge, Germany, in comparison to three former studies from 1978 onwards. Parasit Vectors 2012, 5:268.

31. Hildebrandt A, Pauliks K, Sachse S, Straube E: Coexistence of Borrelia spp. and Babesia spp. in Ixodes ricinus ticks in Middle Germany. Vector Borne Zoonotic Dis 2010, 10:831-837.

32. Fingerle V, Munderloh UG, Liegl G, Wilske B: Coexistence of ehrlichiae of the phagocytophila group with Borrelia burgdorferi in Ixodes ricinus from Southern Germany. Med Microbiol Immunol 1999, 188:145-149.

33. Vogerl M, Zubrikova D, Pfister K: Prevalence of Borrelia burgdorferi s. I. in Ixodes ricinus ticks from four localities in Bavaria, Germany. Berl Munch Tierarztl Wochenschr 2012, 125:401-406.

34. Tappe J, Strube C: Anaplasma phagocytophilum and Rickettsia spp. infections in hard ticks (Ixodes ricinus) in the city of Hanover (Germany): Revisited. Ticks Tick Borne Dis 2013, 4:432-438.

35. Estrada-Peña A, Bouattour A, Camicas J-L, Walker AR: Ticks of domestic animals in the Mediterranean region: a guide to identification of species. Zarazoga: University of Zaragoza; 2004.

36. Janecek E, Mietze A, Goethe R, Schnieder T, Strube C: Bartonella spp. infection rate and B. grahamii in ticks. Emerg Infect Dis 2012, 18:1689-1690.

37. Strube C, Schicht S, Schnieder T: Borrelia burgdorferi sensu lato and Rickettsia spp. infections in hard ticks (Ixodes ricinus) in the region of Hanover (Germany). Berl Munch Tierarztl Wochenschr 2011, 124:512-517.

38. Rijpkema SG, Molkenboer MJ, Schouls LM, Jongejan F, Schellekens JF: Simultaneous detection and genotyping of three genomic groups of Borrelia burgdorferi sensu lato in Dutch Ixodes ricinus ticks by characterization of the amplified intergenic spacer region between $5 \mathrm{~S}$ and 23 S rRNA genes. J Clin Microbiol 1995, 33:3091-3095.

39. Burri C, Moran Cadenas F, Douet V, Moret J, Gern L: Ixodes ricinus density and infection prevalence of Borrelia burgdorferi sensu lato along a North-facing altitudinal gradient in the Rhone Valley (Switzerland). Vector Borne Zoonotic Dis 2007, 7:50-58.

40. Gern L, Douet V, Lopez Z, Rais O, Cadenas FM: Diversity of Borrelia genospecies in Ixodes ricinus ticks in a Lyme borreliosis endemic area in Switzerland identified by using new probes for reverse line blotting. Ticks Tick Borne Dis 2010, 1:23-29.

41. Marie-Angele P, Lommano E, Humair PF, Douet V, Rais O, Schaad M, Jenni L, Gern L: Prevalence of Borrelia burgdorferi sensu lato in ticks collected from migratory birds in Switzerland. Appl Environ Microbiol 2006, 72:976-979.
42. Schicht S, Schnieder T, Strube C: Rickettsia spp. and coinfections with other pathogenic microorganisms in hard ticks from northern Germany. J Med Entomol 2012, 49:766-771.

43. Schicht S, Junge S, Schnieder T, Strube C: Prevalence of Anaplasma phagocytophilum and coinfection with Borrelia burgdorferi sensu lato in the hard tick Ixodes ricinus in the city of Hanover (Germany). Vector Borne Zoonotic Dis 2011, 11:1595-1597.

44. Gray JS, Dautel H, Estrada-Pena A, Kahl O, Lindgren E: Effects of climate change on ticks and tick-borne diseases in europe. Interdiscip Perspect Infect Dis 2009, 2009:593232.

45. Gern L, Rouvinez E, Toutoungi LN, Godfroid E: Transmission cycles of Borrelia burgdorferi sensu lato involving Ixodes ricinus and/or I. hexagonus ticks and the European hedgehog, Erinaceus europaeus, in suburban and urban areas in Switzerland. Folia Parasitol (Praha) 1997, 44:309-314.

46. Fukunaga M, Takahashi Y, Tsuruta Y, Matsushita O, Ralph D, McClelland M, Nakao M: Genetic and phenotypic analysis of Borrelia miyamotoi sp. nov., isolated from the ixodid tick /xodes persulcatus, the vector for Lyme disease in Japan. Int J Syst Bacteriol 1995, 45:804-810.

47. Geller J, Nazarova L, Katargina O, Jarvekulg L, Fomenko N, Golovljova I: Detection and genetic characterization of relapsing fever spirochete Borrelia miyamotoi in Estonian ticks. PLoS One 2012, 7:e51914.

48. Wodecka B: Significance of red deer (Cervus elaphus) in the ecology of Borrelia burgdorferi sensu lato. Wiad Parazytol 2007, 53:231-237.

49. Rollend L, Fish D, Childs JE: Transovarial transmission of Borrelia spirochetes by lxodes scapularis: a summary of the literature and recent observations. Ticks Tick Borne Dis 2013, 4:46-51.

50. Richter D, Debski A, Hubalek Z, Matuschka FR: Absence of Lyme disease spirochetes in larval Ixodes ricinus ticks. Vector Borne Zoonotic Dis 2012, 12:21-27.

51. Gardiner WP, Gettinby G: A weather-based prediction model for the life-cycle of the sheep tick, Ixodes ricinus L. Vet Parasitol 1983, 13:77-84

52. Mejlon HA, Jaenson TG: Seasonal prevalence of Borrelia burgdorferi in Ixodes ricinus in different vegetation types in Sweden. Scand I Infect Dis 1993, 25:449-456.

53. Suss J, Klaus C, Gerstengarbe FW, Werner PC: What makes ticks tick? Climate change, ticks, and tick-borne diseases. J Travel Med 2008, 15:39-45.

54. Stanek G: Pandora's Box: pathogens in Ixodes ricinus ticks in Central Europe. Wien Klin Wochenschr 2009, 121:673-683.

55. Bingsohn L, Beckert A, Zehner R, Kuch U, Oehme R, Kraiczy P, Amendt J: Prevalences of tick-borne encephalitis virus and Borrelia burgdorferi sensu lato in Ixodes ricinus populations of the Rhine-Main region, Germany. Ticks Tick Borne Dis 2013, 4:207-213.

56. Pichon B, Kahl O, Hammer B, Gray JS: Pathogens and host DNA in Ixodes ricinus nymphal ticks from a German forest. Vector Borne Zoonotic Dis 2006, 6:382-387.

57. Pichon B, Rogers M, Egan D, Gray J: Blood-meal analysis for the identification of reservoir hosts of tick-borne pathogens in Ireland. Vector Borne Zoonotic Dis 2005, 5:172-180.

doi:10.1186/1756-3305-7-441

Cite this article as: Tappe et al:: Revisited: Borrelia burgdorferi sensu lato infections in hard ticks (Ixodes ricinus) in the city of Hanover (Germany). Parasites \& Vectors 2014 7:441.

\section{Submit your next manuscript to BioMed Central and take full advantage of:}

- Convenient online submission

- Thorough peer review

- No space constraints or color figure charges

- Immediate publication on acceptance

- Inclusion in PubMed, CAS, Scopus and Google Scholar

- Research which is freely available for redistribution 